\title{
POLÍTICAS DE SAÚDE MENTAL E ABERTURA PARA O FUTURO
}

\author{
MENTAL HEALTH POLICIES AND OPENING \\ TO THE FUTURE
}

\section{POLÍTICAS DE SALUD MENTAL Y APERTURA PARA EL FUTURO}

\author{
Antônia Regina Ferreira Furegato ${ }^{1}$
}

Como citar este artigo: Furegato ARF. Políticas de saúde mental e abertura para o futuro. Rev baiana enferm. 2018;32:e27578.

A Organização Mundial da Saúde (OMS) e a Organização Pan-americana de Saúde (OPAS) apoiam governos para fortalecer e promover a saúde mental da população. Em 2013, na Assembleia Mundial da Saúde, aprovou-se o Comprehensive Mental Health Action Plan for 2013-2020. Trata-se de um compromisso de todos os Estados-membros da OMS, na tomada de medidas específicas para melhorar a saúde mental e contribuir para a realização de um conjunto de metas globais. O plano tem, na sua base, o entendimento de que a saúde mental é um estado de bem-estar no qual a pessoa realiza suas próprias habilidades, consegue lidar com as tensões normais da vida, trabalha de forma produtiva e é capaz de fazer contribuições para a sua comunidade ${ }^{(1)}$.

A OMS entende que saúde mental e bem-estar são fundamentais para nossa capacidade coletiva e individual, como seres humanos, para pensarmos, nos emocionar, interagir uns com os outros, ganhar e aproveitar a vida. Nesta base, a promoção, proteção e restauração da saúde mental podem ser consideradas como preocupações essenciais de indivíduos, comunidades e sociedades em todo o mundo. Entende também que é vital não apenas proteger e promover o bem-estar mental dos cidadãos, mas também atender às necessidades de pessoas com transtornos mentais definidos ${ }^{(1)}$.

O objetivo global do Plano de Ação vigente está focado nos direitos humanos, buscando promover o bem-estar mental, prevenir transtornos mentais, fornecer cuidados, aprimorar a recuperação, reduzir a mortalidade, a morbidade e as deficiências em pessoas com transtornos mentais. Para isso, reforça a importância de liderança eficaz e governança para a saúde mental que forneça serviços abrangentes e responsivos de saúde mental e psiquiatria, integrados à rede de serviços de saúde, assim como fortaleça sistemas de informação, evidências e pesquisa sobre saúde mental ${ }^{(1)}$.

Na mesma linha da OMS, neste ano de 2018, em comemoração ao dia do enfermeiro, o International Council of Nurses (ICN) enfatiza a saúde como um direito humano. Explora questões de acesso à saúde e o impacto do cuidado de qualidade nos resultados de saúde e na qualidade de vida da população.

Enfermeira. Professora Titular. Professora Colaboradora Sênior do Departamento de Enfermagem Psiquiátrica e Ciências Humanas da Escola de Enfermagem de Ribeirão Preto da Universidade de São Paulo. Ribeirão Preto, São Paulo, Brasil. 
Propõe que as práticas sejam centradas na pessoa, para se obter os melhores resultados. Focaliza a importância do cuidado de enfermagem que, mais do que o tratamento de uma doença que pode ser totalmente impessoal, deve ser centrado na pessoa com suas necessidades, considerando o contexto onde a pessoa vive ${ }^{(2)}$.

No processo de Reforma Psiquiátrica brasileira, a crescente demanda por cuidados em saúde mental impulsiona a sua integração e articulação com a atenção básica em saúde. A experiência desse modelo, nos últimos anos, mostra uma tendência para que os serviços deixem de funcionar centrados em si mesmos e assumam uma perspectiva de ações em rede, voltadas para os recursos do território, mantendo a configuração da atenção psicossocial.

No site do Ministério da Saúde (MS), observa-se que as políticas públicas de atenção à saúde mental hoje preconizam: redução de leitos hospitalares e a progressiva extinção dos manicômios; investimento em atenção básica com foco também na saúde mental (Programa de Saúde da Família, grupos de Terapia Comunitária e outros); atenção especializada a dependentes químicos e loucos infratores; formação de recursos humanos para trabalhar em saúde mental; participação da comunidade na elaboração das políticas e no controle social; criação e manutenção de serviços como os Centros de Atenção Psicossocial (CAPs) e Serviços Residenciais Terapêuticos (SRT).

Além disso, investem nos serviços de pronto atendimento, urgência e emergência bem como nas internações em hospitais gerais. Dessa forma, o MS entende que a saúde mental não está dissociada da saúde geral e investe sistematicamente em todos os pontos da rede. Estimula todos os profissionais da área a reconhecerem as demandas de saúde mental presentes em diversas queixas relatadas pelos pacientes que chegam aos serviços de saúde, em especial da Atenção Básica. Cabe, portanto, aos profissionais, o desafio de perceber e intervir sobre essas questões ${ }^{(3-4)}$.

O MS aprovou, em dezembro de 2017, algumas mudanças na Política Nacional de Saúde Mental ${ }^{(4)}$. Apesar de estabelecer diretrizes para o fortalecimento da Rede de Atenção Psicossocial (RAPS), a resolução tem recebido críticas dos adeptos mais radicais da reforma psiquiátrica em vigência. Entretanto, o cenário atual é de que 3\% da população sofre algum distúrbio psiquiátrico, 6 a 8\% da população sofre consequências decorrentes do uso e abuso de álcool e drogas, especialmente nos casos de comorbidades psiquiátricas, fato que tem enorme impacto nas políticas de saúde mental.

Tendo em vista a extinção progressiva dos manicômios, os benefícios do governo "de volta para casa", o retorno à convivência com a família, os programas extra-hospitalares de ressocialização em funcionamento, com equipes especializadas, bem como os demais benefícios oferecidos em saúde mental, são necessárias avaliações muito bem estruturadas. É imprescindível que se mostre o quanto de autonomia os ex-internos dos manicômios e os novos casos atendidos nos serviços de saúde mental e psiquiatria da rede de saúde de fato adquiriram ou se essas pessoas apenas deixaram de ser dependentes da instituição psiquiátrica para terem outros tipos de dependência.

Além disso, após a implantação e vivência prática de duas décadas da reforma e sua inserção na rede de serviços de saúde, importa agora olharmos em torno e procurarmos conhecer novas abordagens, novas propostas que estão surgindo, deixando de lado a polarização entre o modelo médico e o modelo da reforma, para abrir espaços e prosseguir no aperfeiçoamento dos programas de saúde mental, tal como propõe a OMS.

\section{Referências}

1. Organização Mundial da Saúde. Organização Pan-americana de Saúde. Brasil. OPAS/OMS apoia governos no objetivo de fortalecer e promover a saúde mental da população [Internet]. Brasília; 2018 [cited 2018 May 2]. Available from: https://www.paho.org/bra/index.php?option=com_content\&view=article\&id=5263: opas-oms-apoia-governos-no-objetivo-de-fortalecer-e-promover-a-saude-mental-da-populacao\&Itemid=839 
2. International Council of Nurses. Nurses a voice to lead: health is a human right [Internet]. Genebra (CHE); 2018 [cited 2018 May 2]. Available from: http://www.icn.ch/publications/2018-nurses-a-voice-to-lead-health-is-a-human-right/

3. Brasil. Ministério da Saúde. Saúde mental e atenção básica [Internet]. Brasília; 2018 [cited 2018 May 3]. Available from: http://dab.saude.gov.br/portaldab

4. Brasil. Ministério da Saúde. Secretaria de Atenção à Saúde. Legislação em Saúde Mental - 2004 a 2010. Edição XII Colegiado de Coordenadores de Saúde Mental. Brasília; 2010.

Recebido: 7 de agosto de 2018

Aprovado: 7 de agosto de 2018

Publicado: 25 de outubro de 2018

A Revista Baiana de Enfermagem utiliza a Licença Creative Commons - Atribuição-NãoComercial 4.0 Internacional.

https://creativecommons.org/licenses/by-nc/4.0/

Este artigo é de acesso aberto distribuído sob os termos da Licença Creative Commons (CC BY-NC).

Esta licença permite que outros remixem, adaptem e criem a partir do seu trabalho para fins não comerciais. Embora os novos trabalhos tenham de lhe atribuir o devido crédito e não possam ser usados para fins comerciais, os usuários não têm de licenciar esses trabalhos derivados sob os mesmos termos. 